San Antonio Review • San Antonio Review (Issue I | Winter 2017)

\title{
Mountain Smoke
}

\author{
Alex Z. Salinas
}

Published on: Nov 25, 2017

Updated on: Aug 22, 2020

License: Creative Commons Attribution 4.0 International License (CC-BY 4.0). 
1.

I remember the promise of the mountains, the alpine summer breeze clearing our pores, the entranced look you gave me on Highway 14

Remember the chip factory next to the hotel? That's where you would've transferred You said all I needed to do was find a job

2.

I remember our first lunch, spaghetti and meatballs There was something passed in our gaze, something dangerous - beautiful and dangerous

I talked about her You talked about him We knew the stakes

Remember how I held you after the fallout? I said we had to move on, that we had destroyed, and now we have to create

3.

Then there's you

I remember your eyes sparkling like sunlit jade under the bridge, the cool twilight rain washing the soles of our feet

I had pitted you against her And the damage was done

You were the only one who knew the whole story Remember how we left ours unfinished?

$* * *$

I remember something else now

The mountains, they never promised me a damn thing.

San Antonian Alex Z. Salinas earned a bachelor's degree in political science from St. Mary's University in 2011. His flash fiction has appeared online in Every Day Fiction, Nanoism, escarp, 101 Words, 101 Fiction, and ZeroFlash. He has also had poetry published in the San Antonio Express-News. 